\title{
Flipped IT Teaching in Technical and Vocational Education
}

\author{
Wen-Lung Tsai*, Xin-Ying Liu, Jun-Ping Wei, Ju-Ying Wang \\ Department of Information Management, Asia Eastern University of Science and Technology, New Taipei, Taiwan \\ *Corresponding author.Email: wltsai@mail.aeust.edu.tw
}

\begin{abstract}
Since the emergence of the concepts and technology of cloud computing in the first decade of the 21st century, there has been a burgeoning development in applications of information technology, such as mobile devices, big data, Internet of things, and artificial intelligence. Currently, students of IT-related disciplines rely not only on books for knowledge and skills but also on learning activities performed with the help of information and communication technology (ICT) applications such as smartphones and tablets. This change represents a key milestone in the integration of information technology with teaching. The flipped classroom approach is a student-centered teaching model that has evolved from the integration of IT and teaching over the past decade. This model has not only changed students' mode of learning but also revolutionized the traditional teacher-centered teaching. Students now can use various ICT tools to prepare their lessons in advance and teachers can conduct classroom activities to stimulate students' critical thinking and innovative approach, and develop their communication, collaborative, and implementation skills. The new teaching model is characterized by its student-centered approach, individualized instruction, and ability to make students proactive. Although different disciplines in the education system of Taiwan have begun to promote the flipped classroom model, it is still in a nascent stage in the country's IT education. This study explains in detail key concepts as well as concerns and misplaced notions that have arisen during the implementation of flipped classroom teaching in IT-related education. Thus, this study will serve as a useful reference for promotion of the flipped classroom teaching strategy in Taiwan's technical and vocational education.
\end{abstract}

Keywords: Information technology education, Flipped teaching, Teaching transformation, Multimedia lesson plans.

\section{INTRODUCTION}

Teacher-centered teaching models in the past involved delivering lectures mostly by referring to books. However, with the rapid development of information technology, digital learning based on cloud computing and mobile devices has gradually become a mainstream practice in education. It has exerted a significant impact on school education in terms of the learning environment, learning style, and the use of teaching materials. Learning theories have been applied in digital learning to enhance learning outcome. With the constant emergence of new applications of information technology and proactive promotion of artificial intelligence (AI) and financial technology (FinTech) by the government, $\mathrm{AI}$ and FinTech services are set to bring about yet another wave of impact on information civilization. In this world of booming technology, digital mobile devices have greatly influenced different segments of the contemporary society. The information needed for everyday life no longer comes from a single discipline, but is retrieved through interdisciplinary sources of knowledge. However, computer-aided learning through digital mobile devices and the Internet has become an inevitable trend. With the rapid development of IT and radical changes in educational philosophy, concepts and teaching model of the flipped classroom have revolutionized the traditional teaching, encouraging collaborative learning and practical knowledge, thereby catalyzing student-centered education. The author of the present study is currently engaged in the transformation process of traditional teaching materials into digital learning videos. Digital learning videos are usually considered the main component of the flipped classroom, involving constant innovation in the content and the format of learning. The use of multimedia in educational materials, aided by engaging sounds and visual effects, 
can result in effective dissemination of the intended knowledge and stimulation of learners' interests.

\section{LITERATURE REVIEW}

The concept of the flipped classroom was introduced in the 1990s but its actual implementation in the education sector only began in the early years of the twenty-first century. Hantla [1] used self-made educational videos for the makeup lessons of absent students, allowing students to browse through courses online. Given its satisfactory outcome, this practice was extended to the formal curriculum. The flipped classroom model, also known as flipped teaching or flipped learning, transformed the traditional model of teachers' teaching in the classrooms and students completing their assignments at homes. To better cater to students' needs while designing teaching activities, Hantla [1] introduced the idea of mastery learning and named it "flipped mastery classroom."

In a flipped classroom model, students have to first read teaching materials provided by teachers and then write down key points or questions before the start of the class. During lessons, teachers switch from the conventional, unidirectional mode of teaching to conducting student-centered bidirectional learning activities such as discussions, debates, group discussions, and case reports. In the classroom, teachers play various roles, including encouraging students, answering questions, and providing clarifications. They help students to develop correct concepts, stimulate their thinking, guide them to solve problems, and encourage the application of knowledge.

Bond [2] stated that four key elements of the flipped classroom are F-L-I-P, which stand for flexible learning environments, (student-centered) learning culture, intentional content, and professional educator. To satisfy the above four elements, teachers not only need to have good teaching ideas and design abilities, but also good information literacy and application abilities. Since digital learning materials are now usually treated as a means to stimulate students' learning interests, teachers can produce digital materials using video recording software such as Camtasia Studio, EverCam, and HyperCam, and then upload videos on YouTube or digital learning platforms such as Moodle, Blackboard, or XOOPS for students to learn from them. Teachers can also opt for existing digital materials for students' selflearning. For example, a study by Rueda and Serrano [3] mentioned that the Khan Academy founded in 2006 has developed many personalized YouTube online materials and provided teachers with some online digital materials, which have become an important teaching database for implementation of the flipped classroom. In addition, teachers can utilize teaching materials from the flourishing massive open online courses (MOOCs) to implement the flipped classroom model [3].

\section{CASE IMPLEMENT}

In interdisciplinary teaching, multimedia technology can also be used to convert the teaching content into animated digital materials, or to further design them as interactive materials. These can be combined with actions on the Internet for learners to view, thereby enhancing their learning efficiency.

The author of this study is currently designing FinTech-related animations and animated games, which are presented through multimedia production, and is applying the concept of the flipped classroom in teaching. Digital learning videos are used to reflect on traditional lecture-based teaching models. The teaching content disseminated through audio-visual effects allows learners (including members of the education sector) to prepare for the content of the lesson and contemplate about the message it intends to convey. Apart from achieving the purpose of lesson preparation, it enables learners to attain consistency when thinking about the value direction they intend to achieve in the future, while also learning more about FinTech. Furthermore, learning outcomes can be assessed through interactive games, thus demonstrating whether learners have acquired the relevant knowledge and information in various aspects of FinTech applications. This would be especially beneficial for start-up companies and university students in financerelated disciplines.

The design of pre-class activities usually involves watching videos on a network platform. However, the implementation of the flipped classroom model in FinTech-related courses involves not only watching videos, but also taking part in additional learning activities such as quizzes and reading teachers' self-made or existing teaching materials. In regard to in-class teaching activities, they would not only include group discussions and learning activities but also other teaching activities, such as role play and case discussions, as extended learning activities. Results have shown that these activities can promote students' proactive and group cooperative learning as well as enhance their confidence and problem-solving skills.

Learning outcomes can show different dimensions. This study showed that four participating students were very satisfied with the learning content of this pedagogical model whereas 75 per cent of the students were extremely satisfied with case discussions. The study also found that with the help of the flipped classroom, teachers can assess students' individual progress, discover their needs and difficulties at an early stage, and guide them to set their own learning pace. Teachers were also able to provide students with timely personal guidance, thus helping them to achieve their learning goals. 


\section{DISCUSSION AND CHALLENGES}

The flipped classroom is currently on the rise in the education system of Taiwan. However, a few misconceptions have arisen in the course of its implementation. They include:

- Flipped classroom is the same as asking students to watch videos before lessons.

- Educational videos are not necessarily produced or assigned by teachers, which means students are allowed to watch online videos freely.

- Flipped classroom must involve student discussions.

- Flipped classroom model will achieve better teaching outcome than traditional teaching.

- MOOCs are the same as the flipped classroom.

These misconceptions must first be clarified before the flipped classroom model is implemented in the teaching curriculum of IT disciplines; only then can we reap the full benefits of this model. The issues arising from the implementation of the flipped classroom in IT education need to be analyzed from the perspective of teachers and students.

\subsection{Issues Concerning the Recording of Pre- class Educational Videos}

Based on the idea of the flipped classroom, students must watch videos or read information related to the course content before lessons. However, the technology and equipment required for recording videos would exert a great pressure on teachers. Some schools or organizations would provide hardware and software for the production of digital learning materials and offer consultation on IT. If teachers can make a good use of these resources, the issues concerning the recording of educational videos can be resolved. Apart from that, currently there are many simple software available for the production of educational videos, such as EverCam and Camtasia, which can help teachers to produce educational videos.

Teachers sometimes think that they can give teaching assistants the full authority to record videos. Nevertheless, it is teachers themselves who are responsible for delivering the video content. Therefore, it is impossible to rely completely on teaching assistants. Teachers must first devote adequate time and efforts to learn video production skills and then instruct teaching assistants to record videos in accordance with the teaching philosophy formulated by the teachers.

If teachers cannot produce all videos, they can consider using existing online videos. However, they must consider the relevance of the content of these videos to their teaching. If no such videos are available, it is not necessary to insist on having one because the key concept of the flipped classroom is to change students' mode of learning. Thus, asking students to even read teaching materials such as books or e-books before lessons is also a kind of pre-class preparation.

\subsection{Students' Unwillingness to Prepare for Classes or Carry out Placement Assessment}

To motivate students to complete pre-class teaching activities designed by teachers, such as watching videos, and carry out placement assessment before lessons, following strategies can be adopted:

- The pre-class overview must explain the importance of pre-class activities.

- The content of in-class graded assignments or tests can be designed in relation to the content of pre-class preparation activities.

Students should be able to answer and score easily after they have completed the pre-class preparation. This can motivate students to carry out the required preparation and thus help them to cultivate the habit of self-directed learning.

\subsection{Students' Unwillingness to Participate in Class Discussions}

Possible reasons for students not willing to participate in class discussions include the following:

- Questions asked by teachers are too abstract and not concrete enough.

- Teachers have inadequate experience in leading class discussions.

- Students are not used to expressing their personal opinions in class.

- Students are worried about appropriateness of what they speak in the class and whether their teachers or classmates would laugh at them.

In these circumstances, teachers should create a free and open atmosphere for discussion in order to relieve the stressed students from voicing their opinion among teachers and other students. The adaptation of an incentive strategy for speaking in the class or the use of a suitable format for holding small group discussions can facilitate students to slowly develop the habit of participating in discussions. Moreover, teachers should reflect on whether they should stick to the role of only lecturing and thus depriving students of speaking opportunities by talking constantly. 


\subsection{Lack of Standardization in Teaching Activities}

Since the flipped classroom is a new concept, teachers engaged in traditional teaching have not been instructed on how to design teaching activities for a flipped classroom. As teaching activities for use in the flipped classroom are currently not standardized, teachers would be concerned about the required number of these activities. In this aspect, we suggest that teachers should strike a balance. After all, the core spirit of the flipped

classroom is to change students' learning style and the pedagogical model. There is no need to stick to the volume or progress of the course content. Instead, developing students' proactive learning and self-learning ability is what matters.

\subsection{The Timing of Using the Flipped Classroom}

The flipped classroom is just one of many teaching strategies, and it should not be the only teaching strategy in a course. If teaching activities implemented in the flipped classroom are conducted in every lesson, this may reduce the learners' willingness to learn. We suggest the flipped classroom is conducted for a few lessons in each course depending on the nature of the content in each module. Teachers should also design a variety of teaching activities such as quizzes, assignments, debates, and case discussions followed by progressive and appropriate teaching activities based on the course content.

\section{CONCLUSION}

Existing IT education is still to a large extent conducted by using traditional classroom teaching strategies. Nevertheless, the traditional classroom teaching model is no longer popular among students of the current generation. Moreover, its learning effectiveness has often been questioned. Understanding students' learning interest is the only way to stimulate their zest for learning and enhance learning outcomes. The flipped classroom is in line with the learning style of e-generation students as it utilizes the information technology to change "teaching and learning" activities and habits of students and teachers. The flipped classroom is also characterized by its student-centered concepts and its ability to inspire students' proactive learning, encourage collaborative learning, provide individual instruction, and achieve effective learning. For this reason, its application in the teaching of IT disciplines can enhance students' critical thinking skills, develop their communication and cooperation abilities, make them independent learners, and ultimately enhance their information literacy skills.

\section{REFERENCES}

[1] B. F. Hantla, Book Review: Flip your classroom: Reach every student in every class every day, 2014.

[2] M. Bond, Facilitating student engagement through the flipped learning approach in K-12: A systematic review. Computers \& Education, 151, 103819, 2020.

[3] K. Rueda, O. Serrano, Online training for the strengthening of mathematical pre-knowledge mediated by Khan-Academy platform, Journal of Physics: Conference Series. IOP Publishing 1161(1) (2019)

[4] K. Julia and K. Marco, Educational scalability in MOOCs: Analysing instructional designs to find best practices. Computers \& Education, 161, 104054, 2021. 